\title{
Compassion Stress and the Qualitative Researcher
}

\author{
Kathleen B. Rager
}

Human subjects are carefully protected in the research process. However, the same consideration is not currently being given to the qualitative researcher, even those investigating topics that are likely to elicit powerful emotions. The role of researcher's emotional responses and the self-care strategies that, in some circumstances, are appropriate for the researcher and other research support personnel have not received the attention they deserve in qualitative research literature. Based on experience in conducting research on the topic of self-directed learning and breast cancer, and on the limited literature available, the author makes the case for the use of strategies such as counseling, peer debriefing, and journal writing as means of dealing with the potential for "compassion stress" as experienced by the researcher and other research support personnel. She also suggests that the preparation of social science researchers should include information on appropriate self-care strategies.

Keywords: emotions and qualitative research; self-care strategies for researchers

$\mathbf{T}$ he participants in my qualitative study of the self-directed learning of breast cancer patients were protected carefully. I met all the requirements of the institutional review board to conduct the study and to obtain clearance to proceed with data collection via personal interviews with breast cancer patients. Before each interview began, I carefully explained the study and had each woman sign the required informed consent form. It indicated, among other things, that participation would not harm her in any way and that she could withdraw from the study at any time. No one did withdraw. In fact, most of the participants indicated that talking to me had been very beneficial to them.

The question that was not asked as I began my study but that I wish to raise at this time is whether researchers should not also attend to themselves in the process. No thought was given to ensuring that I would take steps to address the impact on me as I conducted such emotionally laden research. By reflecting on my experience and on the literature related to this issue, I hope to shed light on the need for change in this regard.

The 15 months I spent completing my dissertation research were some of the most stressful, emotional, yet rewarding times of my life. What I have learned since then is that my experience in conducting this type of research was not unique. Gilbert (2001b) has observed, "Attention paid to emotions in qualitative research largely has focused on protecting participants from negative effects. It has not been on doing the same for researchers" (p. 11).

QUALITATIVE HEALTH RESEARCH, Vol. 15 No. 3, March 2005 423-430

DOI: $10.1177 / 1049732304272038$

(C) 2005 Sage Publications 


\title{
EMOTIONS IN THE RESEARCH PROCESS
}

Until recently, the emotional responses of researchers to their work have not been perceived positively. According to Jaggar (1996), "Because values and emotions had been defined as variable and idiosyncratic, positivism stipulated that trustworthy knowledge could be established only by methods that neutralized the values and emotions of individual scientists" (p. 167). Harris and Huntington (2001) have suggested that "mainstream, arguably malestream, approaches to research theorizing and practice have often ignored or marginalized the importance of emotions in the research process" (p. 129). Wincup (2001) explained the lack of attention in the literature by stating,

\begin{abstract}
Despite major shifts in social science research, emotionality is still constructed in opposition to rationality and professionalism, and the importance of emotions is denied. Consequently, talking about the personal impact of conducting research is a task with which many academics (including feminists) are uncomfortable and therefore avoid. This affects the novice researcher by leaving him or her unprepared for the level of emotional engagement that social research requires. (p. 19)
\end{abstract}

\section{THE ROLE OF THE QUALITATIVE RESEARCHER}

Within the qualitative paradigm, the researcher has been acknowledged as the instrument through which data are collected and analyzed. Maykut and Morehouse (1994) called for the qualitative researcher to "assume the posture of indwelling" (p. 25). They defined this as "being at one with the persons under investigation, walking a mile in the other person's shoes, or understanding the person's point of view from an empathic rather than a sympathetic position" (p. 25). Furthermore, they suggested that the human-as-instrument is the single data collection instrument that is sensitive enough and complex enough to capture the multifaceted elements of a human person or experience.

In fact, it is the ability to be with others that distinguishes the qualitative researcher. When a person indwells in a situation, he or she is with the person, i.e., the qualitative researcher is experiencing the world in a similar way with the participant. (p. 26)

Rew, Bechtel, and Sapp (1993) reflected a similar position in suggesting,

The inherent value of human beings and their intersubjective experiences underscore the significance of the use of self-as-instrument in qualitative inquiry. No other entity could fully capture the multidimensionality and intricacy of the human experience. (p. 301)

\section{EMOTIONS AS ESSENTIAL TO THE PROCESS}

According to Gilbert (2001b), there is "increasing comfort with emotions in qualitative research" (p. 4). Indeed, some researchers (Harris \& Huntington, 2001; Jaggar, 
1996; Kleinman \& Copp, 1993; Maykut \& Morehouse, 1994; Sciarra, 1999) have suggested that emotion is essential to the investigative process in the qualitative paradigm. "Because entering the meaning-making world of another requires empathy, it is inconceivable how the qualitative researcher would accomplish her goal by distancing herself from emotions" (Sciarra, 1999, p. 44). In addition, Gilbert (2001b) suggested that the researcher must connect both cognitively and emotionally with study participants. "It is not the avoidance of emotions that necessarily provides for high quality research. Rather, it is an awareness and intelligent use of our emotions that benefits the research process" (p. 11).

\section{MY EXPERIENCE}

I selected the topic of the self-directed learning of women with breast cancer, because I thought the study could make a contribution to my field, adult education. Very few researchers have explored self-education in a crisis situation, such as when diagnosed with breast cancer. I was also motivated by the desire to work on a topic that would hold my interest for the duration of the study and about which I had strong feelings. As a woman and the mother of three daughters, I was both drawn to and yet fearful of the topic of breast cancer. Although no one in my immediate family had the disease, some friends and distant relatives were survivors. I knew at the outset of my research that it would be an emotionally charged experience, but I thought that the benefits of the study outweighed any reservations I had regarding the emotional costs to me.

What I could not anticipate as I began my research was that I would become a cancer survivor during the process. In the second month of the study, I was diagnosed with melanoma skin cancer. That experience definitely heightened my stress, but at the same time, it strengthened my connection with the women I interviewed several months later. I never considered not completing the breast cancer study because of my situation. In fact, I became more committed to it, and I now see that it helped me to heal emotionally from my own life-threatening situation.

Stuhlmiller (2001) has suggested, "To get the story, the researcher must conduct himself or herself in a way conducive to fostering disclosure from the narrator. This may require the researcher to reveal something about himself or herself" (p. 67). I did share with participants that I, too, was a cancer survivor; however, I must admit that I did not do it to enhance the interview process. I told the women I interviewed when and if it felt natural and appropriate to do so. I had a strong sense of the need for me to be open and honest in my relationships with them but, at the same time, to be careful not to take the focus off their experiences as we interacted.

The stories that the study participants told were moving, at times frightening, and often inspirational. Looking back, I think that it would have been dishonest of me to not react emotionally to their painful stories. In fact, tears were part of every interview. What I found was that the women could discuss their cancer and their learning experiences unemotionally. However, they were invariably moved to tears when they talked about the people who had helped them and those who had not. We cried together as I "experienced the world in a similar way with the participant" (Maykut \& Morehouse, 1994, p. 25). 
For example, I was touched by the story of one participant's first breast cancer support group meeting. Her husband attended with her. When they went around the group with introductions, she could not speak, because she was crying.

So he [her husband] sat there and told the story and talked. And the one thing I remember is that he just put his hand on my leg and said, "We were diagnosed with breast cancer in September." (Rager, 2000, p. 111)

I cried with another participant but for the opposite reason. This participant indicated how devastated she was by the fact that her mother and other close family members failed to contact her before her surgery. "They don't understand that that contact would carry you through lots of moments" (Rager, 2000, p. 110). In other interviews with breast cancer patients, I heard about a husband who now wanted divorce, a boyfriend who ended a relationship, a husband who asked his wife to sleep in another room so that he would not be disturbed by the side effects of her chemotherapy, and about what it is like to be left waiting for 2 hours for your first chemotherapy session because the staff forgot about you. I believe that my emotional responses to the participants' stories were natural and appropriate, and in no way compromised the research process. Rather, I concur with Gilbert's (2001b) testimony: "Our research efforts were enriched by our personal and emotional engagement in the research process" (p. 11).

Fortunately, early in my process, I encountered the suggestion from another breast cancer researcher that steps should be taken to effectively deal with the stress that can accompany inquiry into such an emotionally laden subject. Iocolano (1994) suggested counseling as a means of processing the feelings and stress that the researcher might experience. When I began the interviews for my study, I started seeing Nan, a counselor at the university at which I was employed. I conducted 3 interviews to pilot test the interview protocol and 13 interviews to collect data for analysis. Talking things over with Nan during that 2-month period was extremely helpful. I remember having the distinct feeling of being much lighter as I left each session with her. I think debriefing with her was one of the smartest things I did for myself during that period.

However, that is not all that I did. I used journal writing and relaxation techniques, and I met regularly with a peer reviewer with whom I processed my feelings as well as the progress of the study. I also have a wonderful network of friends and family members whose support and encouragement were invaluable. When I recently reread my journal, I was amazed at how sick I was through most of the process. I was experiencing real and psychosomatic symptoms on a regular basis, including breast pain, abdominal pain, and problems with my digestive system. I also noted in my journal that my health improved as soon as the interviews were complete. After that, I wrote, "I appreciate how I feel. It's been a long time .. . The stress was taking its toll." I believe that I was experiencing "compassion stress" (Pickett, Brennan, Greenberg, Licht, \& Worrell, 1994, p. 250) regarding to the women I had interviewed. Also referred to as the "cost of caring" (Figley, 1999, p. 4), it was certainly exacerbated by the normal stress associated with completing a dissertation as well as by the life events I was experiencing at that time. 


\section{IMPACT ON OTHERS}

I was not the only one who was affected emotionally by my study. When I talked to Rosemary, the woman who was transcribing my interviews, she, too, indicated that she was reacting emotionally to the material. She reported that at times as she transcribed, she was moved to tears. She indicated that sometimes it was necessary for her to take time away from the material because it became too emotional for her. My peer reviewer also indicated that reading a draft of the study affected her. She reported experiencing psychosomatic symptoms, such as breast pain, as she read and said that she really appreciated what I had been going through, especially in view of the added stress of my own cancer.

In hindsight, I realize that everyone who was involved in the study should have been prepared for the potential for strong emotional responses to the material. Gilbert (2001a) suggested that it is common to overlook the possibility that support personnel might be affected and that there is "an ethical obligation to prepare them for possible emotional reactions, both positive and negative, they may have to the content and/or to the research process" (p. 158).

Ultimately, even my doctoral committee members commented on their emotional responses to reading my final document. They reported that I had been successful in my writing at allowing the participants voices to be heard and that they, too, had been touched by their stories. I strongly agree with Wincup's (2001) comment:

My emotional awareness encouraged me to listen more closely to the accounts of the women I interviewed, and to think carefully about the ways I could do justice to the women's stories as I created my ethnographic account. (p. 29)

In terms of the participants' emotional reactions to the research, many of them indicated that talking to me had been a beneficial experience. They said that they had learned a great deal from telling their stories and that it had given them a new perspective on how they had handled their breast cancer. Other researchers (Gilbert, 2001b; Stuhlmiller, 2001) have reported similar reactions from interview participants. Stuhlmiller suggested that "the research interview can help a person clarify his or her situation and arrive at some helpful solutions or therapeutic outcomes" (p. 64). Gilbert also addressed the positive impact on participants, stating, "Qualitative research interviews may actually have a therapeutic effect on participants who feel empowered by their participation rather than vulnerable" (p. 13).

\section{NEED FOR AWARENESS AND SAFEGUARDS}

In spite of the stressful nature of the research study, I characterized the dissertation process in my journal as a "peak experience." I think that I was fortunate to have identified and used resources that helped me process the emotions that the experience triggered. I also think, however, that more needs to be done to formalize the safeguards that should be part of the process when a researcher takes on an emotionally laden subject like breast cancer. 
Just as one is required to address the protection of the human subjects who will participate in the study, one should address the protection of the researcher as well.

If the qualitative researcher is to be the research instrument, then he or she must be fully aware of the nature of that instrument. What is at issue, then, is the impact of immersion in an emotionally charged environment, and the elicitation of painful, and inspirational stories, and the telling of these stories. (Gilbert, 2001b, p. 11)

Likewise, as Harris and Huntington (2001) maintained, "The effort of working analytically with emotions is justified both in terms of the quality of work we produce and of the importance of maintaining our own emotional well-being" (p. 142).

Some interesting insights can be gained from looking at the literature pertaining to therapists who deal with trauma patients. Unlike qualitative researchers who deal with emotionally laden topics, those in the therapeutic community are not allowed to work in similar situations without strategies in place for handling their emotional reactions. To cite one example, the requirements for a certified trauma counselor include at least 50 hours of personal counseling and/or therapy, 240 hours of training, and 2,000 hours of trauma counseling experience (Williams \& Sommer, 1999).

Terms like compassion fatigue, compassion stress, and secondary traumatic stress have been used to label the "natural, predictable, treatable, and preventable unwanted consequence of working with suffering people" (Figley, 1999, p. 4). Four prevention strategies have been identified as successful in dealing with secondary stress responses among psychotherapists. They are

comprehensive education about stress and coping, development and maintenance of personal and professional support networks, attention to self-care and life enjoyment activities, and maintenance of realistic goals, limits, and boundaries regarding interactions with clients. (Pickett et al., 1994, p. 250)

Furthermore, it is suggested that the specific interventions used should be tailored to the needs and preferences of the individual therapist (Pearlman \& Saakvitne, 1995, p. 165).

\section{STRATEGIES FOR EMOTIONAL WORK}

It would seem that qualitative researchers might benefit from similar consideration when they engage in emotionally laden research. Some are beginning to call for attention to the emotional work that needs to accompany research of this type. According to Jaggar (1996), "Accepting the indispensability of appropriate emotions to knowledge means no more (and not less) than that discordant emotions should be attended to seriously and respectfully rather than condemned, ignored, discounted, or suppressed" (p. 183). Harris and Huntington (2001) wrote, "Thinking through and working with the emotional rather than just the technical aspects of our interactions in interviews is an important, and we would argue often neglected, consideration" (p. 141). In addition, Kleinman and Coop (1994) suggested, "Ignoring or suppressing feelings are emotion work strategies that divert our attention from the cues that ultimately help us understand those we study" (p. 33).

The practical strategies that are found in the literature mirror the ones I stumbled on or came to intuitively as I attended to my self-care while conducting my 
TABLE 1: Recommendations for Coping With Compassion Stress

\begin{tabular}{|c|c|c|}
\hline Target Audience & Recommendations & Potential Benefits \\
\hline Novice researchers & $\begin{array}{l}\text { Provide information in qualitative research } \\
\text { courses; teach self-care strategies }\end{array}$ & $\begin{array}{l}\text { Increased awareness; prepared- } \\
\text { ness; appropriate self-care } \\
\text { planning when conducting } \\
\text { emotionally laden research }\end{array}$ \\
\hline $\begin{array}{l}\text { Qualitative } \\
\text { researchers }\end{array}$ & $\begin{array}{l}\text { Individual self-care planning; use of strate- } \\
\text { gies such as journal writing, counseling, } \\
\text { peer debriefing, careful sequencing of } \\
\text { intense interviews, social support net- } \\
\text { works, balance between work and per- } \\
\text { sonal life }\end{array}$ & $\begin{array}{l}\text { Better management of self-care; } \\
\text { processing of feelings; reduc- } \\
\text { tion of avoidance; reduction of } \\
\text { compassion stress }\end{array}$ \\
\hline Support staff & $\begin{array}{l}\text { Discussion of potential for experiencing } \\
\text { compassion stress; monitoring; debriefing }\end{array}$ & $\begin{array}{l}\text { Preparedness; processing of feel- } \\
\text { ings; stress reduction }\end{array}$ \\
\hline
\end{tabular}

study. According to Maykut and Morehouse (1994), it is critical that at least some of the strategies assist the researcher in reflective thinking, because this aspect is considered a requirement for the qualitative research process.

Specifically, Rew and colleagues (1993) suggested, "The qualitative researcher engaged in descriptive inquiry should record biases, feelings, thoughts, and historical circumstances in a journal or diary" (p. 301). Wincup (2001) recommended peer discussion, as it "can provide reassurance and helps to overcome feelings of isolation by recognizing that your own emotional experiences are not unique" (p. 29). Pickett et al. (1994) posited that debriefing is "a critical process for data collectors engaged in research focused on violent, disturbing, or sensitive topics" (p. 252). In addition, Gilbert (2001b) recommended seeking out "social and emotional support" (p. 12) as well as spacing interviews with enough time in between to reduce the intensity, which can become overwhelming. Finally, Sciarra (1999) highlighted "the challenge facing qualitative researchers in maintaining the proper boundary between themselves and their participants" (p. 46) and suggested, along with Iocolano (1994), that talking with others, whether in counseling or with peers or close associates, can assist with the continuous process of renegotiating this boundary. Other stress management techniques intended to achieve a balance between work and personal lives, such as social events, hobbies, travel, and exercise, also have a significant role to play. O'Halloran and Linton (2000) have compiled an excellent list of resources that address the social, emotional, cognitive, physical, spiritual, and vocational aspects of self-care.

\section{RECOMMENDATIONS}

From my perspective, as well as from the perspective of the literature that addresses this topic, what is needed is a set of guidelines designed to protect all those involved in conducting emotionally charged research (Gilbert, 2001b). In addition, the training and education given to research students should include information on the emotional nature of qualitative research under these circumstances (Wincup, 2001). Ultimately, what is needed is recognition that the researcher and all those involved in conducting studies that are likely to involve significant emotional reaction need to plan for their own emotional self-care during the research process. I have summa- 
rized the recommendations stemming from my experience and from the literature in Table 1 . As for me, I value the experience I shared with the 16 women who participated in my study. It was not easy, but it was well worth both my intellectual and emotional efforts. My hope is that qualitative researchers who come after me will have an easier time with regard to dealing with their emotional responses in similar circumstances and that, unlike my experience, this important aspect of their research will not be left to chance.

\section{REFERENCES}

Figley, C. R. (1999). Compassion fatigue: Toward a new understanding of the costs of caring. In B. H. Stamm (Ed.), Secondary traumatic stress: Self-care issues for clinicians, researchers, E educators (2nd ed., pp. 3-28). Lutherville, MD: Sidran.

Gilbert, K. (2001a). Collateral damage? Indirect exposure of staff members to the emotions of qualitative research. In K. R. Gilbert (Ed.), The emotional nature of qualitative research (pp. 147-161). Boca Raton, FL: CRC Press LLC.

Gilbert, K. (2001b). Introduction: Why are we interested in emotions? In K. R. Gilbert (Ed.), The emotional nature of qualitative research (pp. 3-15). Boca Raton, FL: CRC Press LLC.

Harris, J., \& Huntington, A. (2001). Emotions as analytic tools: Qualitative research, feelings, and psychotherapeutic insight. In K. R. Gilbert (Ed.), The emotional nature of qualitative research (pp. 129-145). Boca Raton, FL: CRC Press LLC.

Iocolano, C. F. (1994). A qualitative study of four women during the first four months after surgery for breast cancer. Dissertation Abstracts International, 55 (09), 3816B.

Jaggar, A. M. (1996). Love and knowledge: Emotion in feminist epistemology. In A. Garry \& M. Pearsall (Eds.), Women, knowledge, and reality: Explorations in feminist philosophy (2nd ed., pp. 166-190). New York: Routledge.

Kleinman, S., \& Copp, M. A. (1994). Emotions and fieldwork. Newbury Park, CA: Sage.

Maykut, P., \& Morehouse, R. (1994). The qualitative posture: Indwelling. In P. S. Maykut (Ed.), Beginning qualitative research: A philosophic and practical guide (pp. 25-40). London: Falmer.

O'Halloran, T. M., \& Linton, J. M. (2000). Stress on the job: Self-care resources for counselors. Journal of Mental Health Counseling, 22(4), 354-364.

Pearlman, L. A., \& Saakvitne, K. W. (1995). Treating therapists with vicarious traumatization and secondary traumatic stress disorders. In C. R. Figley (Ed.), Compassion fatigue: Coping with secondary traumatic stress disorder in those who treat the traumatized (pp. 150-177). New York: Brunner/Mazel.

Pickett, M., Brennan, A. W., Greenberg, H. S., Licht, L., \& Worrell, J. C. (1994). Use of debriefing techniques to prevent compassion fatigue in research teams. Nursing Research, 43(4), 250-252.

Rager, K. B. (2000). The self-directed learning of women with breast cancer: A qualitative study. Dissertation Abstracts International, 61 (11), 4258.

Rew, L., Bechtel, D., \& Sapp, A. (1993). Self-as-instrument in qualitative research. Nursing Research, 42(5), 300-301.

Sciarra, D. (1999). The role of the qualitative researcher. In M. Kopala \& L. A. Suzuki (Eds.), Using qualitative methods in psychology (pp. 37-48). Thousand Oaks, CA: Sage.

Stuhlmiller, C. M. (2001). Narrative methods in qualitative research: Potential for therapeutic transformation. In K. R. Gilbert (Ed.), The emotional nature of qualitative research (pp. 63-80). Boca Raton, FL: CRC Press LLC.

Williams, M. B., \& Sommer, J. F., Jr. (1999). Self-care and the vulnerable therapist. In B. H. Stamm (Ed.), Secondary traumatic stress: Self-care issues for clinicians, researchers, $\mathcal{E}$ educators (2nd ed., pp. 3-28). Lutherville, MD: Sidran.

Wincup, E. (2001). Feminist research with women awaiting trial: The effects on participants in the qualitative research process. In K. R. Gilbert (Ed.), The emotional nature of qualitative research (pp. 17-35). Boca Raton, FL: CRC Press LLC.

Kathleen B. Rager, Ph.D., is an assistant professor of adult education at the University of Oklahoma, Norman. 